\title{
Deutung einer mifsverstandenen Stelle im Mahãvastu.
}

In der von Senart besorgten Ausgabe des Mahāvastu findet man in II, S. 189-195 unter dem Titel 'Kaṇțakasya vyākaranam' die Geschichte des Rosses Kaṇthaka, wie es nach der Trennung von seinem Herrn, dem Bodhisattva, mit Chandaka nach Kapilavastu zurückgekehrt, in tiefer Trauer den Genuß aller Nahrung verweigert und so den Hungertod starb. Zum Lohne für diese fromme Tat wurde er nach seinem Tode im Himmel der 33 Götter als 'devaputra' wiedergeboren. Nun traf es sich einmal, daß der ehrwürdige Mahā-maudgalyāyana einen Besuch bei den Göttern abstattete und dort den Devaputra Kanthaka in dessen Herrlichkeit anscluaute. Nachdem Maudgalyāyana, voll Entzuckung, die Pracht der himmlischen Wohnung Kanțhakas hervorgebohen hat ${ }^{1}$ ), fragt er:

kimi tvaṁ karma karitvāna pūrva anyāsu jātisu,

kena kuçalamülena trāyastrimçopapadyatha ${ }^{2}$ )

kim tvam karma karitvāna pürve mänuṣake bhave,

kena kuçalamūlena vipakam an»bhos' imam.

kena tvaya ayam labdhko āyur varnọo ${ }^{3}$ yaço balam, rddhim ca parivaram ca anubhosi amanușam.

Es folgen noch einige Fragen desselben Inbaltes bis Zeile 10, wo es heißt:

so devaputro atmana Maudgalyāyena prochito, praçnam prșto viyakkarși sthavirasyeti me çrutam.

Aus der Antwort des Kanţbaka seien hier nur einzelne Strophen angefibrt:

tasyaiva adarçanena Çäkyaputrasya çrīmato, gurukabãdham utpadye ${ }^{4}$ ) tato kalam karomy aham.

1) Die Pālifassung der Erzählung findet man in Vimānavalthu S. $81 \mathrm{ff}$.

2) So zu lesen statt odyatha.

3) So \%u lesen mit B.; vgl. S. 194, 15: tena mayā ayam labdham àyu varṇa(m) yaço balán.

4) So zu lescn für khuraābādha utpadyet, das Pāli hat alatthain garukābāadhain. 


\section{Etwas weiter:}

tam karmam kuçalam krtva yat tam upacitam purä, tena kuçalakarmeṇa vipäkam anubhomy ${ }^{1}$ ) aham. bhoga ca me utpadyensu ye kecît manusi priyā, deva ca me namasyanti teșàm c'apacito ${ }^{2}$ ) aham.

Nach diesem Schluß der Antwort Kanthakas, macht der Erzähler die folgende moralische Betrachtung, welche im gedruckten Texte also lautet:

tasmim cittam prasādetha daksin̄iyeșu tädŗ̧̣à, paçyati rakṣabhütena karmam upacitam çubham.

Die zweite Halbstrophe ist unverständlich infolge einer verkehrten Worttrennung. Richtig ist:

paçya tirakṣabhütena karmam upacitam çubham.

Paçya ist ein Imperativ; tivakșabhūta ist eine mißlungene Sanskritisierung' eines prāk. tiracchabhüta 'tierisches Wesen, Tier'; vgl. Pāli tiracchūna, skr. tiryañc, tiryagyona usw. Die Übersetzung ist: 'Sieh! (wie) ein Tier Lohn einer guten Handlung sich erworben (eig. gesammelt) hat'. Kurios ist die var. 1. in C: paçyantiratnacchatrabhūtena. Man braucht nur die Silben tna, tra und das $n$ in pacyanti zu streichen und sieht die ältere gute Lesart vor sich: paçya tiracchabhütena. Der Urheber der Lesart in $\mathrm{C}$ hat nicht erkannt, daß paçya ein Imperativ ist und dadurch wußte er mit raccha keinen Weg; gedankenlos hat er nun, unbekümmert um das Metrum, ein paar Silben eingefügt, so daß zwei an sich verständliche, aber hier ganz unpassende Wörter, ratna und chatra, zum Vorschein kommen.

Auch die erste Halbstrophe ist nicht in Ordnung. Fur tasmim lese man tasmã. Tádrçam ist eine ungeschickte Sanskritisierung, wohl von tadisu. Die Zeile läßt sich also übersetzen: 'Darum habe man im Geiste Wohlgefallen an solchen Verehrungswürdigen!

Über die im vorhergehenden gerügten Mißgriffe wird sich keiner wundern, dem es nicht unbekannt ist, wieviele fast unglaubliche Fehler die Zusammensteller der nordbuddhistischen Schriften bei der Sanskritisierung ursprünglich prākṛtischer Texte begangen haben. Ein merkwürdiges Bei-

1) Der gedruckte Text hat anubhavāmy ahain.

2) So zu lesen statt ca upacito. 
spiel ist vaipañcanika 'Zeichendenter' Mahāvastu I, 207; II, 12; vaipancamika Lalita-vistara 224; vaipañika Mahāvyutpatti (s. Pet. Wtb.), Divyāvadāna 474; alles hervorgegangen aus einem mißverstandenen Präkṛtausdruck *vepañjanika, Pāli veyyañjaniya, Jātaka IV, 233; var. l. veyyañcanika 235, mit unrichtigem ñca für ñja. Das Wort ist natürlich eine $\mathrm{Ab}$ leitung aus vyañjana. Zufällig gibt es im Sanskrit ein Wort vaipañcika in der Bedentung 'Lautenspieler', gebildet von vipañci 'die indische Laute' 1), doch dies bat nichts zu schaffen mit dem buddhistischen vaipañcika.

Bisweilen läßt es sich schwer entscheiden, welche Prākṛtform einem anscheinenden Sanskritansdruck zugrunde gelegen hat. So begegnet uns im gedruckten Text des Divyāvadāna $543 \mathrm{f}$. ein Wort papantika und payantika. Wir dürfen annehmen, daß die wahre Lesung páyattika ist. Der Bedeutung nach entspricht es dem Pāli pacittiya, doch hieraus kann schwerlich payattika entstanden sein; es steht gewissermaBen dem skr. prayaçitta näher. Jedenfalls ist es ein Beispiel einer verfehlten Sanskritisierung.

Aus verschiedenen Grunden darf man es als sicher betrachten, $\mathrm{da} B$ die älteren kanonischen Texte ursprünglich nicht alle in einem und demselben Dialekt verfaßt seien. Daher erklären sich Differenzen in den sanskritisierten Formen. So findet man Mahāvastu II, 44 bhramu (skr. bhrū), während 297 bhrümukha hat. Bhramu stimmt zu Pāli bhamu; dagegen geht bhrümukha (mit falschem $\bar{u}$ ) zurtick etwa auf humuha, das dem Ardha-Māgadhī bhamuha und bhumaya $\bar{a}^{3}$ ) nahesteht, ohne ganz damit identisch zu sein.

Ein wunderlich entstelltes Wort ist anuragata in der formelhaften Verbindung svāgatam anuragatani te Mahāvastu II, 38; svagatam rajño Çuddhodanasya, anurāgatam rajño Çuddhodanasya III, 181. Dies Ungeheuer ist einfach ein verbunztes adurāgata, das im Pāli häufig vorkommt, und zwar in derselben Verbindung, so Jātaka IV, 356: 'svāgatan te mahārāja, atho te adurāgatam', so auch 484 ; VI, 23; Therīgāthā

1) Dies im PW. und CWK. fehlende Wort kommt vor im Drama Pradyumnābhyudaya des Ravivarman S. 4 (Trivandrum Sanskrit Series No. VIII).

2) Pischel, Grammatik der Prakritsprachen 124, 206, 261. 
337. Da alle Hss. in der Lesart anu ubereinstimmen und die Silben $d u$ und $n u$ graphisch ganz verschieden sind, dürfen wir die Bearbeiter der uns uberlieferten Redaktion des Mhv. für die Entstellung verantwortlich stellen.

Zu den ursprünglichen Prākrt-Ausdrücken, welche die Bearbeiter wohl verstanden, aber nicht gehörig sanskritisiert haben, gehört uccagati (uccagitavantah Saddharma-puṇuarīka 382, 12). Dies geht zurïck auf ujjaks; vgl. ved. jakșat 'lachend'; Pāli ujjhagghati, Therīgāthā $74^{1}$ ). Das cca statt jja kann dialektisch sein, aber auch ein Febler. Die Wurzel ist natürlich has.

Utrecht.

H. Kern.

1) Childers hat nur ujjhaggikā 'loud laughter'. 